Bài báo khoa học

\title{
Đánh giá tính dễ bị tổn thương đối với đa thiên tai ở ven biển Trung Trung Bộ
}

\section{Trần Thanh Thủy ${ }^{1}$, Trần Thục ${ }^{1}$, Huỳnh Thị Lan Hương1}

${ }^{1}$ Viện Khoa học Khí tượng Thủy văn và Biến đổi khí hậu; thuybk77@gmail.com; tranthuc.vkttv@gmail.com; huynhlanhuong@gmail.com

* Tác giả liên hệ: thuybk77@gmail.com; Tel.: +84-796071306

Ban Biên tập nhận bài: 05/9/2020; Ngày phản biện xong: 12/10/2020; Ngày đăng: $25 / 10 / 2020$

Tóm tắt: Các thiên tai thường xảy ra đồng thời, hoặc nối tiếp, làm tăng tình trạng dễ bị tổn thương của khu vực chịu tác động. Các tỉnh ven biển Trung Trung Bộ thường xuyên chịu tác động bất lợi của thiên tai điển hình như bão, mưa lớn... Đã có nhiều nghiên cứu về thiên tai và tình trạng dễ bị tổn thương do thiên tai, tuy nhiên, các nghiên cứu đều chỉ mới xét đến thiên tai riêng lẻ, mà chưa xét đến tình trạng dễ bị tổn thương gây bởi nhiều thiên tai xảy ra đồng thời hoặc nối tiếp nhau (đa tổn thương). Bài báo này trình bày kết quả đánh giá định lượng mức độ dễ bị tổn thương ở khu vực ven biển Trung Trung Bộ đối với bão, mưa lớn trong bão và mưa lớn xảy ra sau bão (đa thiên tai). Kết quả cho thấy, $86 \%$ các huyện thuộc Trung Trung Bộ có TDBTT cao và rất cao đối với gió mạnh (GM) hoặc mưa lớn trong bão $(\mathrm{MTB})$ và $50 \%$ đối với mưa lớn sau bão (MSB). Chỉ số TDBTT dao động từ $0,11-0,39$ đối với $\mathrm{GM} / \mathrm{MTB}$ và $0,02-0,47$ đối với MSB. TDBTT gia tăng đối với đa thiên tai, $100 \%$ các huyện có mức độ đa tổn thương cao và rất cao, chỉ số mức độ đa tổn thương $(\mathrm{MV})$ dao động từ $0,18-0,49$. Mức độ đa tổn thương có thể tăng $25 \%-105 \%$ so với TDBTT đối với thiên tai đơn. Do đó, các giải pháp nhằm giảm độ nhạy cảm, tăng nguồn lực của khu vực nghiên cứu là nhiệm vụ cần thiết và cấp bách. Cách tiếp cận của nghiên cứu này đánh giá chi tiết, tổng thể TDBTT không chỉ đối với thiên tai đơn mà còn đánh giá được TDBTT đối với đa thiên tai, cho phép xây dựng bản đồ phân vùng đa tổn thương ở quy mô cấp huyện, giúp ích cho công tác lập kế hoạch, quản lý nguồn lực và điều phối liên huyện, nhằm giảm nhẹ thiệt hại do đa thiên tai gây ra.

Từ khóa: Đa thiên tai; Bão; Mưa lớn; Tính dễ bị tổn thương; Đa tổn thương.

\section{Giới thiệu}

Khu vực Trung Trung Bộ trải dài từ $14^{\circ} 32^{\prime}$ đến $18^{\circ} 05^{\prime}$ vĩ độ Bắc và từ $105^{\circ} 37^{\prime}$ đến 10904' kinh độ Đông, bao gồm 06 tỉnh: Quảng Bình, Quảng Trị, Thừa Thiên-Huế, Đà Nẵng, Quảng Nam và Quảng Ngãi. Với đường bờ biển dài $769 \mathrm{~km}$, Trung Trung Bộ là một trong những khu vực chịu nhiều ảnh hưởng của bão, áp thấp nhiệt đới (ATNĐ). Bão là một trong những loại thiên tai nguy hiểm nhất trong số các thiên tai có nguồn gốc khí tượng thủy văn $[1-3]$. Bão và $A T N Đ$ đổ bộ không chỉ gây ra gió mạnh trực tiếp tàn phá cây cối, nhà cửa, công trình, cơ sở hạ tầng... mà còn đi kèm mưa lớn xảy ra trên diện rộng kêt hợp mưa lớn sau bão gây ra lũ lụt, lũ quét, sạt lở đất bất thường... gây thiệt hại nghiêm trọng về người và tài sản. Điển hình là bão Xangsane (bão số 6 năm 2006), cơn bão rất mạnh đổ bộ và ảnh hưởng trực tiếp đến Thừa Thiên-Huế, Đà Nẵng, Quảng Nam và Quảng Ngãi, gây thiệt hại nặng nề. Sau bão, mưa lớn, lũ dâng cao khiến các tỉnh miền Trung khác cũng bị 
ảnh hưởng, tổng thiệt hại trên 10 nghìn tỉ đồng [4]. Bão Ketsana (bão số 9 năm 2009) là cơn bão rất mạnh và di chuyển nhanh, phạm vi ảnh hưởng rộng, bao trùm toàn bộ 6 tỉnh Trung Trung Bộ và các tỉnh lân cận, bão kèm theo mưa lớn trên diện rộng từ Nghệ An đến Bình Định, Tây Nguyên, thiệt hại ước tính khoảng 14 nghìn tỷ đồng [5].

Trung Trung Bộ là khu vực chịu ảnh hưởng của nhiều thiên tai có liên quan đến bão, xảy ra đồng thời hoặc nối tiếp. Đánh giá tính dễ bị tổn thương (TDBTT) do đa thiên tai đặc biệt là bão, mưa lớn trong bão và sau mưa lớn bão sẽ giúp cho công tác giảm nhẹ TDBTT hiệu quả hơn. Việc giảm nhẹ đa tổn thương có thể đạt được thông qua nhiều hoạt động khác nhau. Trong đó, công tác chuẩn bị, phòng ngừa và giảm thiểu tác động là các hoạt động cốt lõi [6]. Các hoạt động này phụ thuộc vào các chính sách, sự quản lý, điều hành và kinh nghiệm của địa phương [7-8]. Hiệu quả của các hoạt động liên quan đến công tác giảm nhẹ thiệt hại do thiên tai gây ra, đặc biệt là công tác lập kế hoạch, quản lý, điều hành sẽ vẫn bị hạn chế nếu chúng được xây dựng và triển khai theo cách tiếp cận từng thiên tai đơn lẻ [8]. Việc xác định được mức độ đa tổn thương có thể đóng góp cho việc chuẩn bị, lập kế hoạch và quản lý nguồn lực, điều phối liên huyện, giúp giảm nhẹ thiệt hại do đa thiên tai gây ra.

Đánh giá TDBTT dựa trên bộ chỉ số về kinh tế-xã hội-môi trường đã được áp dụng rộng rãi từ những năm 1980 [9]. Tuy nhiên việc đánh giá đa tổn thương mới được cộng đồng quốc tế quan tâm nghiên cứu từ những năm 2000 như đánh giá đa tổn thương của các bờ biển ở Thổ Nhĩ Kỳ đối với nước biển dâng, xói mòn bờ biển và xâm nhập mặn [10], sử dụng GIS để xác định đa tổn thương đối với triều cường, nước biển dâng và xói lở bờ biển cho bờ biển phía tây của Ấn Độ [11], đánh giá đa tổn thương đối với động đất, núi lửa [12], xác định đa tổn thương đối với mực nước biển dâng, sự thay đổi đường bờ và triều cường cho Iran [13]... Tuy nhiên, các nghiên cứu đánh giá đa tổn thương còn rất hạn chế ở Việt Nam. Nghiên cứu này sẽ xác định mức độ đa tổn thương về kinh tế-xã hội-môi trường đối với bão, mưa lớn cho khu vực Trung Trung Bộ. Từ đó xây dựng bản đồ phân vùng đa tổn thương và đưa ra một số kiến nghị về chính sách và các biện pháp trong tương lai nhằm giảm nhẹ thiệt hại do đa thiên tai gây ra.

\section{Phương pháp và số liệu}

TDBTT đại diện cho xu hướng hoặc khuynh hướng của một cộng đồng, hệ thống, hoặc tài sản bị ảnh hưởng bất lợi bởi một hiểm họa nhất định, TDBTT bao gồm độ nhạy cảm và nguồn lực [4]. Để đánh giá TDBTT đối với thiên tai dựa trên bộ chỉ số, việc xác định bộ chỉ số nhạy cảm và nguồn lực đóng vai trò quan trọng. Khi chịu tác động đồng thời của các thiên tai, TDBTT sẽ gia tăng do mức độ nhạy cảm của các đối tượng có nguy cơ bị ảnh hưởng tăng và nguồn lực ứng phó và chống chịu với thiên tai giảm. Phương pháp dưới đây sẽ cho phép xác định được TDBTT đối với thiên tai đơn, mức độ gia tăng TDBTT đối với các thiên tai xảy ra đồng thời hoặc nối tiếp và đa tổn thương.

\subsection{Xác định bộ chỉ số đánh giá tính dễ bị tổn thương và nguồn số liệu}

Bộ chỉ số TDBTT đối với thiên tai bao gồm các chỉ số về độ nhạy cảm và nguồn lực. Tiêu chí lựa chọn các chỉ số đánh giá TDBTT bao gồm: (i) tính sằn có; (ii) có tính toàn diện đối với các lĩnh vực kinh tế, xã hội, vật lý và môi trường; (iii) có tính đại diện đối với thiên tai đang được xem xét.

\subsubsection{Chỉ số độ nhạy cảm}

Độ nhạy cảm phản ánh các yếu tố ảnh hưởng đến hậu quả của thiên tai. Chỉ số nhạy cảm có thể là thuộc tính vật lý, kinh tế, xã hội, văn hóa như cấu trúc tuổi, tuổi thọ công trình, tỷ lệ giới... [4]. Các nhóm chỉ số cấp 1 được lựa chọn gồm: Kinh tế, xã hội, vật lý và môi trường. Chỉ số và nguồn số liệu được chỉ ra trong bảng 1 . 
Bảng 1. Bộ chỉ số về mức độ nhạy cảm.

\begin{tabular}{|c|c|c|c|}
\hline $\begin{array}{l}\text { Chỉ thị } \\
\text { cấp } 1\end{array}$ & Chỉ số cấp 2 & Ý nghĩa & Nguồn số liệu \\
\hline Kinh tế & $\begin{array}{l}\text { Tỷ lệ đóng góp GDP của ngành } \\
\text { nông nghiệp }\end{array}$ & & Kết quả điều tra \\
\hline Xã hội & $\begin{array}{l}\text { - Tỷ lệ người già và trẻ em (0-15 } \\
\text { tuối; trên } 64 \text { tuồi) [15] } \\
\text { - Tỷ lệ hộ nghèo, cận nghèo }\end{array}$ & $\begin{array}{l}\text { - Tỷ lệ người già, trẻ em càng cao, } \\
\text { độ nhạy cảm càng cao, tính dễ bị tổn } \\
\text { thương càng cao. } \\
\text { - Tỷ lệ hộ nghèo, cận nghèo càng } \\
\text { cao, độ nhạy cảm càng cao, tính dễ } \\
\text { bị tồn thương càng cao. }\end{array}$ & $\begin{array}{l}\text { - Kết quả điều } \\
\text { tra dân số năm } \\
2014 \\
-\quad \text { Niên giám } \\
\text { thông kê cấp } \\
\text { huyện năm } 2018\end{array}$ \\
\hline Vật lý & $\begin{array}{l}\text { - Tỷ lệ nhà bán kiên cố } \\
\text { - Tỷ lệ nhà thiếu kiên cố } \\
\text { - Tỷ lẹ̣ nhà đơn sơ } \\
\text { - Khoảng cách đến đường bờ biển } \\
\text { (chỉ áp dụng cho bão và mưa trong } \\
\text { bão) }\end{array}$ & $\begin{array}{l}\text { Tỷ lệ nhà bán kiên cố, thiếu kiên cố } \\
\text { và đơn sơ càng cao, tính dễ bị tồn } \\
\text { thương càng cao. }\end{array}$ & $\begin{array}{l}\text {-Kết quả điều } \\
\text { tra, khảo sát năm } \\
2018 \\
\text { - Cơ sở dữ liệu } \\
\text { bản đồ Việt } \\
\text { Nam }\end{array}$ \\
\hline $\begin{array}{l}\text { Môi } \\
\text { trường }\end{array}$ & $\begin{array}{l}\text { - Tỷ lệ hộ không sử dụng hố xí } \\
\text { hợp vệ sinh } \\
\text { - Tỷ lệ hộ không sử dụng nước } \\
\text { sạch }\end{array}$ & $\begin{array}{l}\text { Tỷ lệ hộ không sử dụng nước sạch } \\
\text { phản ánh mức độ chịu ảnh hương về } \\
\text { ô nhiễm môi trường khi có bão, mưa } \\
\text { lớn xảy ra, tỷ lệ thuận với độ nhạy } \\
\text { cảm. }\end{array}$ & $\begin{array}{l}- \text { Niên giám } \\
\text { thông kê cấp } \\
\text { huyện năm } 2018\end{array}$ \\
\hline
\end{tabular}

\subsubsection{Chỉ số nguồn lực}

Nguồn lực bao gồm năng lực thích ứng và năng lực đối phó. Trong đó, năng lực thích ứng phản ánh khả năng của hệ thống, tổ chức, con người và các sinh vật khác để thích ứng với thiệt hại tiềm tàng, tận dụng các cơ hội hoặc để ứng phó với hậu quả do thiên tai đem lại [14]. Năng lực đối phó là khả năng của con người, tổ chức và hệ thống, sử dụng các kỹ năng, giá trị, niềm tin, tài nguyên và cơ hội có sẵn, để giải quyết, quản lý và khắc phục các điều kiện bất lợi trong ngắn hạn [6]. Các chỉ số nguồn lực được lựa chọn bao trùm các khía cạnh về kinh tế, xã hội, vật lý và mức độ sẵn sàng phòng chống thiên tai (Bảng 2).

Bảng 2. Bộ chỉ số về nguồn lực.

\begin{tabular}{|c|c|c|c|}
\hline $\begin{array}{l}\text { Chỉ số } \\
\text { cấp } 1\end{array}$ & Chỉ số cấp 2 & Ghi chú & Nguồn số liệu \\
\hline Kinh tế & Thu nhập bình quân đầu người & $\begin{array}{l}\text { Mức thu nhập càng cao giúp tăng } \\
\text { khả năng ứng phó và giảm thiểu tổn } \\
\text { thương, rủi ro càng thấp }\end{array}$ & $\begin{array}{l}\text { Kết quả điều tra; } \\
\text { niên giám thống } \\
\text { kê cấp tỉnh/huyện } \\
2018 .\end{array}$ \\
\hline Xã hội & $\begin{array}{l}\text { Y tế } \\
\text { - Số cơ sở y tế/số xã } \\
\text { - Số giường bệnh/10 nghìn dân } \\
\text { - Số cán bộ ngành y dược/10 nghìn } \\
\text { dân } \\
\text { - Tỷ lệ người dân tham gia bảo } \\
\text { hiểm y tế } \\
\text { - Tỷ lệ người dân tham gia bảo } \\
\text { hiểm xã hội }\end{array}$ & $\begin{array}{l}\text { - Hạ tầng y tế và nguồn lực y, bác sĩ } \\
\text { được coi là có ý nghĩa lớn phản ánh } \\
\text { khả năng ứng phó khẩn cấp và giảm } \\
\text { nhẹ rủi ro thiên tai của một khu vực } \\
\text { - Tỷ lệ người tham gia bảo hiểm y tế } \\
\text { và bảo hiểm xã hội càng cao, nguồn } \\
\text { lực ứng phó và khắc phục sau thiên } \\
\text { tai càng lớn } \\
\text { - Tỷ lệ người tốt nghiệp càng cao, } \\
\text { tính dễ bị tổn thương càng giảm, rủi } \\
\text { ro càng giảm. } \\
\text { - Điều kiện thông tin liên lạc tốt, }\end{array}$ & $\begin{array}{l}\text { - Niên giám thông } \\
\text { kê cấp huyện } \\
2018 \text {. } \\
\text { - Kết quả điều tra, } \\
\text { khảo sát năm } 2018\end{array}$ \\
\hline
\end{tabular}




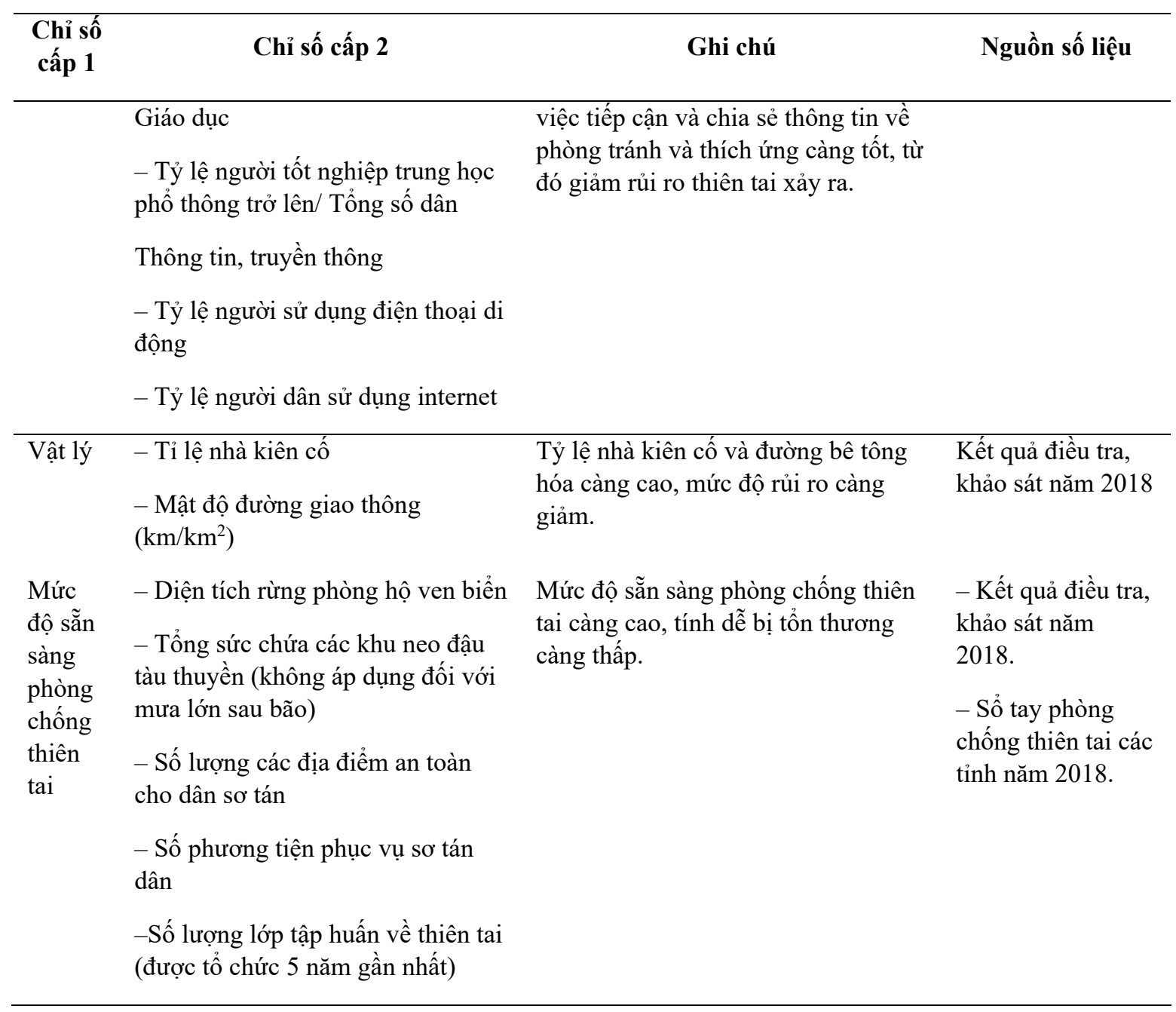

\subsection{Sắp xếp số liệu, chuẩn hóa và xác định trọng số}

Dữ liệu có thể được thu thập từ các báo cáo thống kê, kết quả điều tra, khảo sát thực tế và kết quả các nghiên cứu trước đây. Giá trị các chỉ số được xếp thành ma trận 2 chiều $\mathrm{X}=\{\mathrm{Xij}\} \mathrm{mxn}(\mathrm{i}=1,2, \ldots \mathrm{m} ; \mathrm{j}=1,2 \ldots \mathrm{n})$. Trong đó, $\mathrm{m}$ là số lượng các đơn vị nghiên cứu và $\mathrm{n}$ là số lượng các chỉ số.

Do các chỉ số có đơn vị đo và bậc đại lượng khác nhau nên để so sánh giá trị chỉ số giữa các huyện, cần chuẩn hóa các giá trị này về không thứ nguyên trong khoảng từ 0 đến 1. Trước khi chuẩn hóa cần xác định rõ chỉ số đó tỷ lệ thuận hay tỷ lệ nghịch đối với TDBTT. Nếu quan hệ là đồng biến, chuẩn hóa được thực hiện theo công thức (1), nếu là nghịch biến, thực hiện theo công thức (2) [1].

$$
\begin{gathered}
y_{i j}=\frac{x_{i j}-\operatorname{Min}_{i}\left\{X_{i j}\right\}}{\operatorname{Max}_{i}\left\{X_{i j}\right\}-\operatorname{Min}_{i}\left\{X_{i j}\right\}} \\
y_{i j}=1-\frac{x_{i j}-\operatorname{Min}_{i}\left\{X_{i j}\right\}}{\operatorname{Max}_{i}\left\{X_{i j}\right\}-\operatorname{Min}_{i}\left\{X_{i j}\right\}}
\end{gathered}
$$

Trong đó $\mathrm{y}_{\mathrm{ij}}$ là giá trị chỉ số thứ $\mathrm{j}$ của đơn vị nghiên cứu thứ $\mathrm{i}$ đã được chuẩn hóa; $\mathrm{x}_{\mathrm{ij}}$ là giá trị chỉ số thứ i của đơn vị nghiên cứu thứ $\mathrm{j} ; \operatorname{Min}_{i}\left\{X_{i j}\right\}$ là giá trị chỉ số thứ $\mathrm{j}$ nhỏ nhất theo đơn vị nghiên cứu; $\operatorname{Max}_{i}\left\{X_{i j}\right\}$ là giá trị chỉ số thứ $\mathrm{j}$ lớn nhất theo đơn vị nghiên cứu. 
Mức độ đóng góp của các chỉ số thành phần đối với các chỉ số cấp 1 khác nhau. Do đó, cần xác định trọng số cho từng chỉ số. Có nhiều phương pháp xác định trọng số được sử dụng trong các nghiên cứu. Trong đó, phương pháp tính trọng số không cân bằng do Iyengar và Sudarshan đề xuất năm 1982 đã được ứng dụng để xác định trọng số cho các chỉ số trong báo cáo phát triển con người của Liên Hợp Quốc [17], được áp dụng trong nghiên cứu này. Chỉ số TDBTT tại một đơn vị nghiên cứu được xác định là trung bình cộng của các chỉ số mức độ nhạy cảm và nguồn lực.

\section{3. Đánh giá múc TDBTT đối với thiên tai đơn}

Chỉ số mức độ dễ bị tổn thương tại một đơn vị nghiên cứu được tính theo công thức sau $[12,18]$ :

$$
V_{g}=\frac{S_{g}+C_{g}}{2}
$$

Trong đó $\mathrm{V}_{\mathrm{g}}$ là chỉ số TDBTT gây bởi thiên tai $g$ tại một đơn vị nghiên cứu; $\mathrm{S}_{\mathrm{g}}$ là chỉ số mức độ nhạy cảm trước thiên tai $g$; $\mathrm{C}_{\mathrm{g}}$ là chỉ số nguồn lực ứng phó với thiên tai $g$.

Chỉ số mức độ nhạy cảm $(\mathrm{S})$ và nguồn lực ứng phó $(\mathrm{C})$ được tính theo công thức (4), (5), được kế thừa có chỉnh sửa từ [14] và [16].

$$
M_{g}=\frac{\sum_{j=1}^{n_{1}} w_{j} s_{j}}{n_{1}}
$$

Trong đó $M_{g}$ là chỉ số mức độ nhạy cảm hoặc chỉ số nguồn lực trước thiên tai $g$ tại một đơn vị nghiên cứu; $w_{j}$ là trọng số của chỉ số thị 1 thứ $j ; s_{j}$ là chỉ số cấp 1 thứ $j$ đã chuẩn hóa; $n_{1}$ là số các chỉ số cấp 1 đóng góp vào chỉ số mức độ nhạy cảm hoặc nguồn lực.

$$
s_{j}=\frac{\sum_{k=1}^{n_{2}} w_{k} y_{k}}{n_{2}}
$$

Trong đó $\mathrm{s}_{j}$ là chỉ số mức độ nhạy cảm hoặc nguồn lực cấp 1 thứ $\mathrm{j} ; w_{k}$ là trọng số của thị cấp 2 thứ $k ; y_{k}$ là chỉ số cấp 2 thứ $k$ đã chuẩn hóa; $\mathrm{n}_{2}$ là số các chỉ số cấp 2 đóng góp vào chỉ số cấp 1 .

\section{4. Đánh giá mức độ gia tăng TDBTT đối với đa thiên tai}

Phương pháp đánh giá bán định lượng mức độ tương tác TDBTT đối với các thiên tai đơn khi chúng xảy ra đồng thời hoặc nối tiếp tại từng đơn vị nghiên cứu (Hình 3 ) được kế thừa và phát triển từ $[12,18]$. Mức độ tương tác được đánh giá theo thang điểm từ 0 đến 3 , ứng với 4 mức độ đã xác định (Hình $3 b$ ). Các ô màu là TDBTT gây bởi các thiên tai được đánh giá, được xếp theo đường chéo của ma trận (Hình $3 a$ ). Mức độ tương tác TDBTT được xét theo chiều kim đồng hồ (Hình $3 \mathrm{c}$ ), trọng số tương ứng được điền vào các ô màu trắng $($ Hình $3 \mathrm{a})$.

\begin{tabular}{|l|l|l|l|}
\hline $\mathrm{V} 1$ & $\mathrm{~W}_{12}$ & $\cdots$ & $\mathrm{W} 1 \mathrm{n}$ \\
\hline $\mathrm{W}_{21}$ & $\mathrm{~V} 2$ & $\ldots$ & $\mathrm{W} 2 \mathrm{n}$ \\
\hline$\cdots$ & $\cdots$ & $\cdots$ & $\cdots$ \\
\hline $\mathrm{W}_{\mathrm{n} 1}$ & $\mathrm{~W}_{\mathrm{n} 2}$ & $\cdots$ & $\mathrm{Vn}$ \\
\hline
\end{tabular}

(a)
0: Không ảnh hưởng qua lại

1: Ảnh hưởng qua lại THÂP

2: Ảnh hưởng qua lại TRUNG BÌNH

3: Ảnh hưởng qua lại CAO

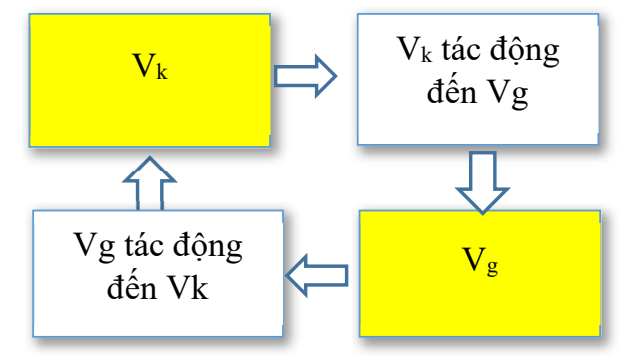

(c)

Hình 3. Ma trận và trọng số đánh giá tác động giữa các thiên tai [18]. 
Dựa trên ma trận đánh giá mức độ ảnh hưởng qua lại giữa TDBTT đối với các thiên tai đơn tại từng đơn vị nghiên cứu, giá trị chỉ số TDBTT phản ánh mức độ tương tác giữa các TDBTT gây bởi thiên tai đơn được xác định theo công thức ()$[8,12]$.

$$
w_{g}=\frac{\sum_{k=1, k \neq g}^{n-1} w_{g, k} \emptyset\left(V_{k}\right)+\sum_{g=1, g \neq k}^{n-1} w_{k, g} \emptyset\left(V_{g}\right)}{6(n-1)} ; \mathrm{g}, \mathrm{k}=1,2, \ldots \mathrm{n}
$$

Trong đó $\mathrm{w}_{\mathrm{g}}$ là mức độ tương tác TDBTT đối với đa thiên tai, có giá trị từ $0-1 ; \mathrm{w}_{\mathrm{g}, \mathrm{k}}$ là mức độ tương tác TDBTT đối với thiên tai $g$ đến TDBTT đối với các thiên tai khác; $\mathrm{w}_{\mathrm{k}, \mathrm{g}}$ là mức độ gia tăng TDBTT đối với các thiên tai khác đến TDBTT đối với thiên tai $g$; $\mathrm{n}$ là số thiên tai tác động đến từng huyện; $\phi\left(\mathrm{V}_{\mathrm{k}}\right)$ là hàm số, có giá trị $=1$ nếu huyện đó bị tổn thương bởi thiên tai $k$ và $=0$ nếu không bị tổn thương.

\subsection{Xác định chỉ số đa tổn thương}

Chỉ số TDBTT đối với thiên tai đơn có xét đến quan hệ với TDBTT đối với các thiên tai đơn khác tại một đơn vị nghiên cứu được xác định theo công thức (7) [12]:

$$
v_{g}^{\prime}=v_{g} *\left(1+w_{g}\right)
$$

Trong đó $v^{\prime}$ g là chỉ số TDBTT đối với thiên tai đơn có xét đến ảnh hưởng qua lại của TDBTT đối với các thiên tai khác, có giá trị từ $0-2 ; v_{g}$ là chỉ số TDBTT đối với thiên tai $g$; $w_{g}$ là mức độ gia tăng TDBTT đối với đa thiên tai, được xác định theo công thức (6).

TDBTT đối với bởi đa thiên tai càng cao nếu chịu tác động của càng nhiều thiên tai xảy ra đồng thời hoặc nối tiếp. Mức độ đa tổn thương được xác định theo công thức sau:

$$
M V=\frac{1}{2}\left(\otimes \sum_{i=1}^{n} v_{g}^{\prime}\right)
$$

Trong đó MV là chỉ số đa tổn thương đối với $\mathrm{n}$ thiên tai có giá trị $0-1 ; v_{\mathrm{g}}$ là chỉ số TDBTT đối với thiên tai đơn có xét đến ảnh hưởng qua lại của TDBTT đối với các thiên tai khác (xác định theo công thức (); n là số thiên tai ảnh hưởng đến đơn vị nghiên cứu. $\otimes$ là hàm tổ hợp xác suất, được xác định theo công thức cộng xác suất của $\mathrm{n}$ giá trị $\mathrm{v}$ ' $\mathrm{g}$. Để chuẩn hóa $\mathrm{MV}$ và đảm bảo $\mathrm{MV}$ luôn lớn hơn v'g, ta có công thức (8).

\section{Kết quả và thảo luận}

\subsection{Tính dễ bị tổn thương đối với thiên tai đơn}

Chỉ số TDBTT đối với thiên tai đơn được xác định cho 64 huyện thuộc 6 tỉnh ven biển ở Trung Trung Bộ. Đối với từng loại thiên tai, 03 nhóm chỉ số độ nhạy cảm về xã hội, môi trường và vật lý có trọng số tương ứng là 0,$34 ; 0,44$ và 0,22 . Mức độ chênh lệch trọng số giữa các nhóm chỉ số không đáng kể, do đó, mức độ đóng góp của các chỉ số về xã hội, môi trường và vật lý đối với TDBTT khá tương đồng.

Đối với các chỉ số về xã hội, nhìn chung Trung Trung Bộ có tỷ lệ người già và trẻ em; tỷ lệ hộ nghèo và cận nghèo cao. $56 \%$ các huyện có tỷ lệ người già, trẻ em trên $40 \%$. Điển hình như các huyện Hòa Vang (Thừa Thiên Huế), Tây Trà, Sơn Trà, Sơn Tây, Minh Long, Ba Tơ, Mộ Đức của Quảng Ngãi... đều có trên tỷ lệ dân số ở độ tuổi trên 64 hoặc dưới 15 tuổi rất cao. $20 \%$ các huyện có tỷ lệ hộ nghèo và cận nghèo trên $40 \%$, tập trung chủ yếu tại các huyện miền núi. Tỷ lệ này có sự chênh lệch lớn giữa thành thị và nông thôn, dao động từ $0,28 \%$ (thành phố Hội An thuộc Quảng Nam) đến 70\% (huyện Trà Bồng của Quảng Ngãi).

Đối với các chỉ số về môi trường, tỷ lệ hộ không sử dụng hố xí hợp vệ sinh và chưa được tiếp cận với nước sạch có sự chênh lệch rõ rệt giữa các huyện miền núi và các huyện ven biển. Một số huyện miền núi như: Tây Giang, Đông Giang, Nam Trà My có tỷ lệ hộ dân không sử dụng nước sạch trên $51 \%$. Nam Trà My cũng là huyện có tỷ lệ hộ không sử dụng hố xí hợp vệ sinh cao nhất Trung Trung Bộ (87,2\%). 
Chỉ số mức độ nhạy cảm đối với GM và MTB của các huyện ở Trung Trung Bộ dao động từ $0,06-0,59.38 \%$ các huyện có chỉ số mức độ nhạy cảm trên 0,25 , tương đương mức độ nhạy cảm rất cao. $47 \%$ các huyện có chỉ só mức độ nhạy cảm từ $0,15-0,25$, tương đương mức độ nhạy cảm cao. Đối với MSB, chỉ số mức độ nhạy cảm dao động từ $0,02-0,76.45 \%$ các huyện có mức độ nhạy cảm cao đến rất cao. Tỷ lệ các huyện có mức độ nhạy cảm cao đến rất cao đối với MSB thấp hơn so với $\mathrm{MTB} / \mathrm{GM}$ do khoảng cách đến đường bờ biển không được xem xét trong nhóm chỉ số vật lý.

Đối với chỉ số nguồn lực, nhóm chỉ số xã hội có trọng số cao nhất $(0,72)$, các nhóm chỉ số còn lại gồm: Kinh tế, vật lý đều nhỏ hơn 0,1 . Mức độ sẵn sàng PCTT có trọng số 0,14 . Do đó, nguồn lực ứng phó với thiên tai phụ thuộc chủ yếu vào nguồn lực xã hội. Chỉ số xã hội càng cao, nguồn lực càng cao, TDBTT càng giảm. Trong số nhóm chỉ số về xã hội, các chỉ số về y tế có trọng số cao nhất $(0,68)$, các chỉ số về giáo dục có trọng số 0,21 và nhóm chỉ số về thông tin liên lạc có trọng số thấp nhất $(0,12)$. Thông tin liên lạc có trọng số thấp nhất không có nghĩa là nó không ảnh hưởng đến TDBTT của từng huyện. Điều kiện thông tin liên lạc tốt, việc tiếp cận và chia sẻ thông tin về phòng tránh và ứng phó càng tốt, hiệu quả giảm nhẹ rủi ro thiên tai xảy ra càng cao.

Đối với GM và $\mathrm{MTB}$, phần lớn các huyện thuộc Trung Trung Bộ có TDBTT cao đến rất cao, chỉ số TDBTT dao động từ $0,11-0,39$. Đối với $\mathrm{MSB}$, chỉ số khoảng cách đến đường bờ biển (trong bộ chỉ số độ nhạy cảm) và tổng sức chứa các khu neo đậu tàu thuyền (trong bộ chỉ số nguồn lực) không được xem xét. Kết quả đánh giá định lượng cho thấy, Trung Trung Bộ có chỉ số TDBTT đối với MSB dao động từ 0,02-0,47 (tương đương TDBTT từ rất thấp đến rất cao). Trong đó, Đà Nẵng có TDBTT đối với mưa lớn sau bão rất thấp, chỉ số TDBTT dưới 0,1 .
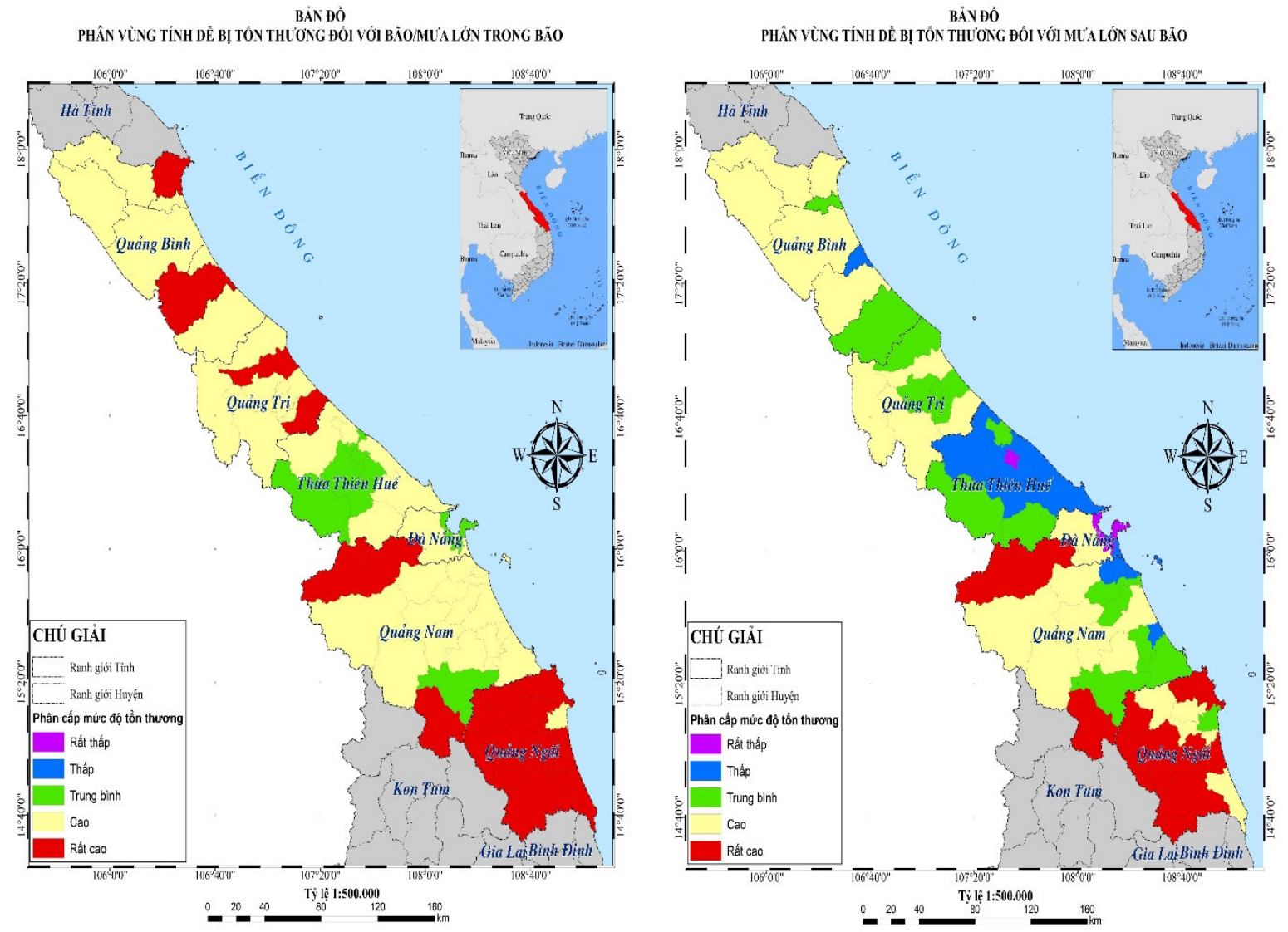

Hình 4. Phân bố không gian tính dễ bị tổn thương đối với thiên tai đơn. 
a)

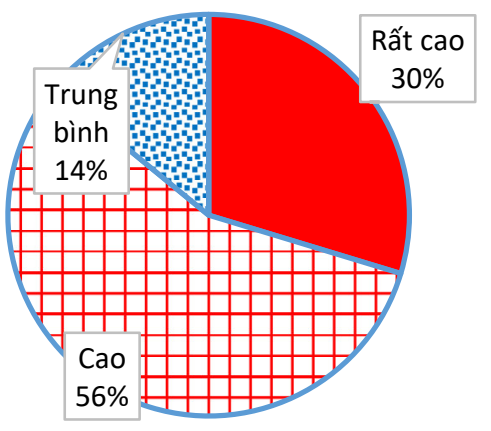

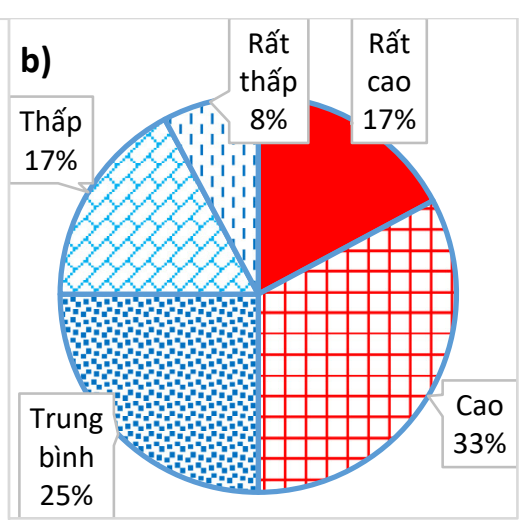

Hình 5. Tỷ lệ mức độ tổn thương đối với bão/mưa trong bão (a) và mưa sau bão (b).

100\% các huyện thuộc Trung Trung Bộ có TDBTT đối với GM/MTB từ trung bình trở lên, trong đó $30 \%$ ở mức rất cao, $56 \%$ ở mức cao. $75 \%$ các huyện có TDBTT đối với MSB từ trung bình trở lên. Sự khác biệt này do việc xem xét thêm chỉ tiêu khoảng cách đến đường bờ biển của các huyện và tổng sức chứa các khu neo đậu tàu thuyền với $\mathrm{GM}$ và MTB.

\subsection{Mức độ gia tăng tính dễ bị tổn thương đối với đa thiên tai}

Khi chịu ảnh hưởng đồng thời của GM, MTB, cả hệ thống ngoài việc ứng phó với GM, phải ứng phó với MTB. Do đó, mức độ TDBTT đối với GM làm gia tăng TDBTT đối với MTB ở mức cao. Tuy nhiên, do trên $96 \%$ các cơn bão ảnh hưiởng khu vực Trung Trung Bộ đều có MTB, người dân địa phương đã có nhiều kinh nghiệm trong việc đồng thời phải ứng phó với GM và MTB. Mức độ gia tăng TDBTT khi hệ thống chịu tác động đồng thời của GM và $\mathrm{MTB}$ được đánh giá ở mức trung bình (trọng số $=2$ ). Tương tự với $\mathrm{MSB}$, mức độ ảnh hưởng của TDBTT đối với GM đến TDBTT đối với MSB được đánh giá ở mức trung bình.

\begin{tabular}{|c|c|c|}
\hline $\begin{array}{l}\text { Gió trong } \\
\text { bão (GB) }\end{array}$ & $\begin{array}{l}\text { GB làm tăng } \\
\text { V đối với } \\
\text { MSB } \\
\text { TRUNG } \\
\text { BÌNH }\end{array}$ & $\begin{array}{l}\text { GB làm } \\
\text { tăng V đối } \\
\text { với MSB } \\
\text { TRUNG } \\
\text { BÌNH }\end{array}$ \\
\hline $\begin{array}{l}\text { MTB làm gia } \\
\text { tăng V đối } \\
\text { với GB } \\
\text { TRUNG } \\
\text { BÌNH }\end{array}$ & $\begin{array}{l}\text { Mưa trong } \\
\text { bão (MTB) }\end{array}$ & $\begin{array}{l}\text { MTB làm } \\
\text { tăng V đối } \\
\text { với MSB } \\
\text { CAO }\end{array}$ \\
\hline $\begin{array}{c}\text { MSB làm } \\
\text { tăng V đối } \\
\text { với GB } \\
\text { THẤP }\end{array}$ & $\begin{array}{l}\text { MSB làm } \\
\text { tăng V đối } \\
\text { với MTB } \\
\text { TRUNG } \\
\text { BÍNH }\end{array}$ & $\begin{array}{c}\text { Mưa sau } \\
\text { bão (MSB) }\end{array}$ \\
\hline
\end{tabular}

\begin{tabular}{|c|c|c|}
\hline $\begin{array}{c}\text { Gió trong } \\
\text { bão (GB) }\end{array}$ & 2 & 2 \\
\hline 2 & $\begin{array}{c}\text { Mưa trong } \\
\text { bão (MTB) }\end{array}$ & 3 \\
\hline 1 & 2 & $\begin{array}{c}\text { Mưa sau } \\
\text { bão (MSB) }\end{array}$ \\
\hline
\end{tabular}

Hình 6. Ma trận đánh giá tương tác giữa TDBTT gây bởi thiên tai đơn.

Khi hệ thống chịu tác động của MTB và MSB, TDBTT của hệ thống gia tăng do nguồn lực đã suy giảm để ứng phó với MTB, mức độ nhạy cảm gia tăng do đã chịu ảnh hưởng của MTB. Các chỉ số độ nhạy cảm vật lý như cấu trúc nhà có thể bị thay đổi, chỉ số về môi trường như tỷ lệ hộ không sử dụng nguồn nước hợp vệ sinh/không sử dụng hố xí hợp vệ sinh có thể gia tăng khi chịu tác động liên tiếp của mưa lớn. Nguồn lực ứng phó với thiên tai cũng có khả năng quá tải như cấu trúc nhà, nguồn lực chống chịu (nguồn lực y tế, sơ 
tán...). Do đó, MTB làm gia tăng TDBTT đối với MSB được đánh giá ở mức cao (trọng số $=3$ ). MSB chủ yếu ảnh hưởng đến khả năng phục hồi sau thiên tai MTB và GM. Do đó, MSB không làm gia tăng độ nhạy cảm đối với MTB và GM nhưng làm giảm nguồn lực khắc phục hậu quả sau các thiên tai này. Mức độ gia tăng được đánh giá là trung bình đối với $\mathrm{MTB}$ và thấp đối với $\mathrm{GM}$. Khi hệ thống chịu tác động của đa thiên tai, mức độ ảnh hưởng qua lại của TDBTT đối với GM thấp nhất là 0,58 , tiếp đến $\operatorname{MSB}(0,67)$ và $\mathrm{MTB}$ là 0,75 .

\section{3. Đa tổn thương đối với các thiên tai xảy ra đồng thời hoặc nối tiếp}

Đa tổn thương được xác định dựa trên TDBTT đối với thiên tai đơn có xem xét khả năng tăng thêm do chịu tác động của các thiên tai xảy ra đồng thời hoặc nối tiếp. Đa tổn thương đối với GM-MTB-MSB được xem xét trong nghiên cứu. Chỉ số đa tổn thương dao động từ $0,18-0,49$. Quảng Bình và Quảng Trị có chỉ số đa tổ thương khá tương đồng, dao động phổ biến từ $0,3-0,4$. Thừa Thiên Huế và Đà Nẵng có chỉ số đa tổn thương thấp hơn (dao động phổ biến từ $0,2-0,3$ ). Quảng Nam có chênh lệch đáng kể giữa các huyện về các chỉ số kinh tế-xã hội- môi trường nên chỉ số đa tổn thương dao động lớn giữa các huyện. Các huyện miền núi như Đông Giang, Tây Giang, Nam Trà My có chỉ số đa tổn thương rất cao (trên 0,4$)$. Nguyên nhân do các huyện này đều có mức độ nhạy cảm cao, nguồn lực ứng phó thấp, ví dụ: Tỷ lệ hộ nghèo từ $37 \%-56 \%$, tỷ lệ người già và trẻ em trên $36 \%$, tỷ lệ hộ không sử dụng nước sạch từ $51-69 \%$, mật độ đường giao thông thấp $\left(0,02-0,1 \mathrm{~km} / \mathrm{km}^{2}\right) \ldots$ Thành phố Tam Kỳ và Hội An, thị xã Điện Bàn có chỉ số đa tổn thương dưới 0,29 . Đây là các địa phương có thu nhập đầu người cao (trung bình trên 3 triệu/tháng), tỷ lệ hộ nghèo thấp (dưới 3\%), tỷ lệ người dân sử dụng điện thoại di động cao (xấp xỉ 85\%), mật độ đường giao thông cao (trên $2 \mathrm{~km} / \mathrm{km}^{2}$ )... Các huyện của tỉnh Quảng Ngãi có chỉ số đa tổn thương dao động trong khoảng $0,43 \pm 0,03$.

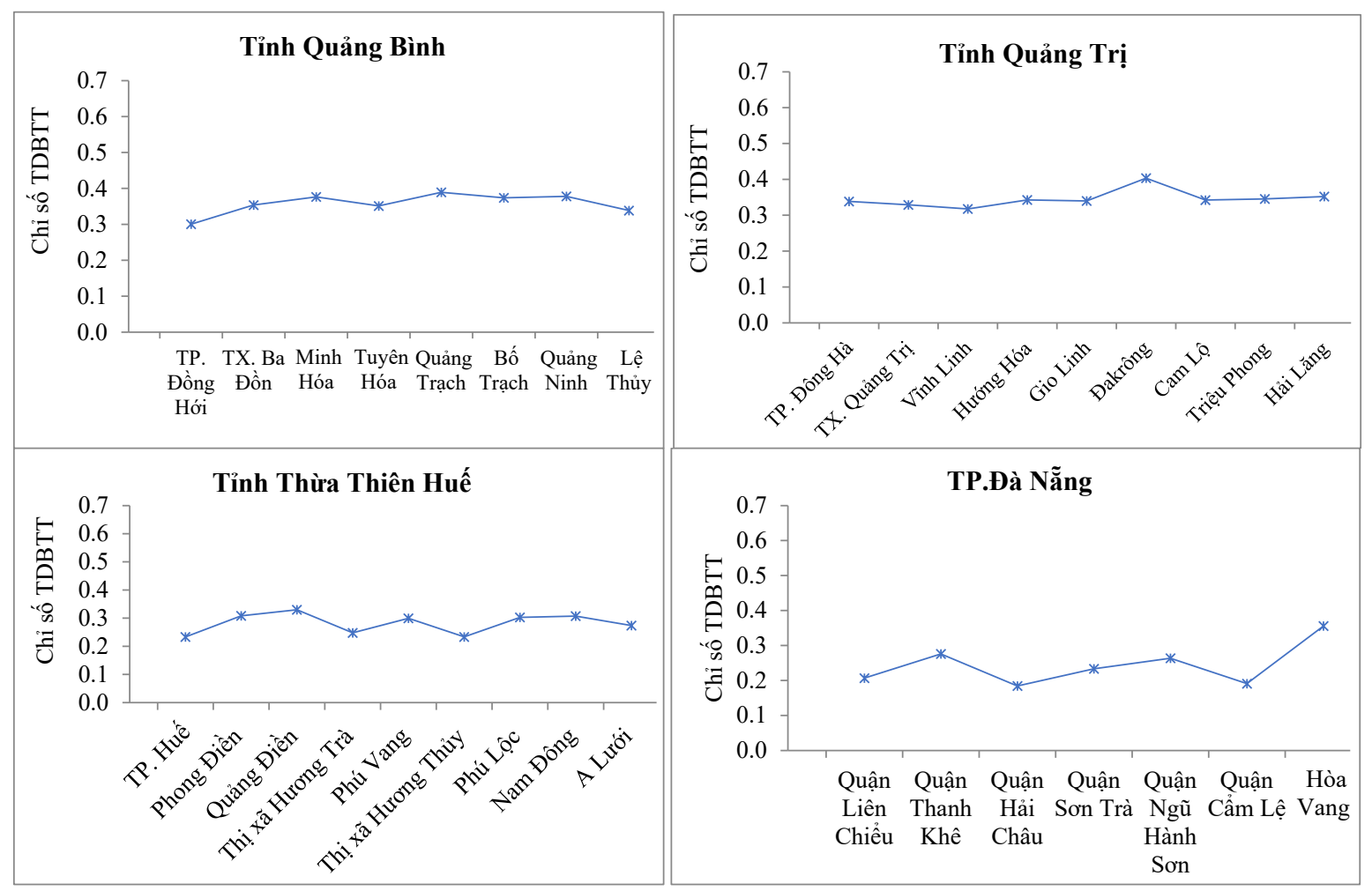




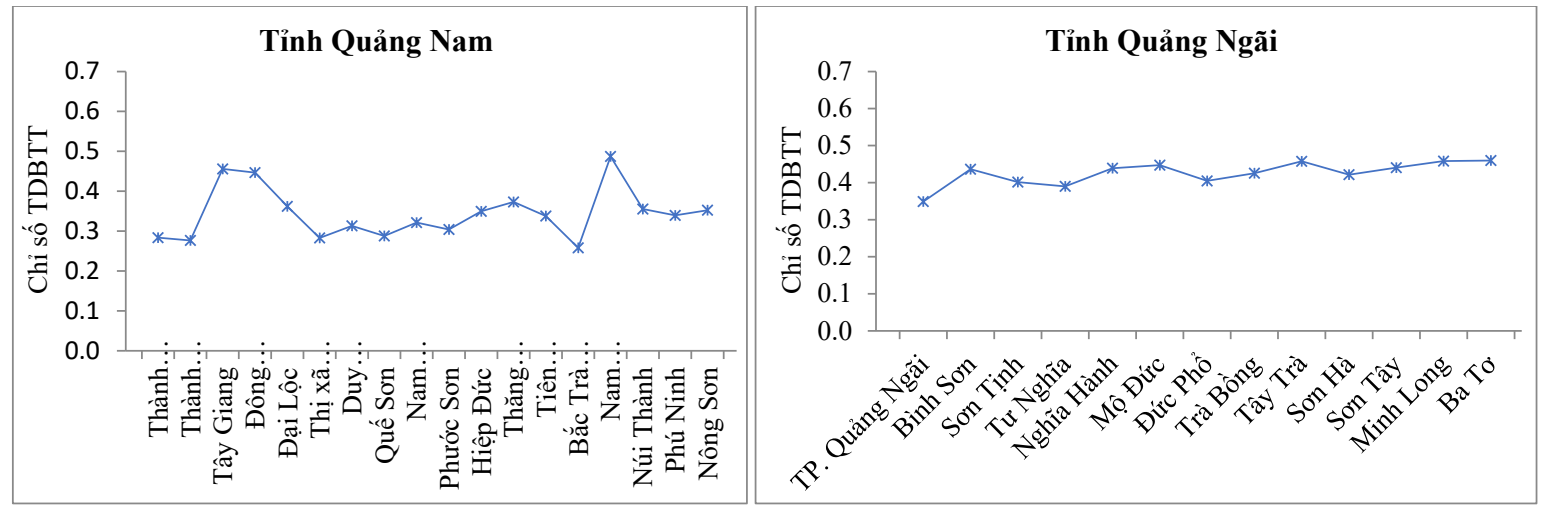

Hình 7. Chỉ số đa tổn thương.

Kết quả phân vùng đa tổn thương cho thấy, $89 \%$ Trung Trung Bộ có mức độ đa tổn thương rất cao (Hình 8). Thành phố Huế, thị xã Hương Thủy, Hương Trà (tỉnh Thừa Thiên Huế) và một số quận ở Đà Nẵng (Liên Chiểu, Hải Châu, Sơn Trà, Cẩm Lệ) có mức độ đa tổn thương cao (chỉ số đa tổn thương từ $0,18-0,25$ ). Các địa phương này có TDBTT đối với MSB rất thấp (chỉ số TDBTT < 0,06), TDBTT đối với GM và MTB trung bình (chỉ số TDBTT từ $0,11-0,15)$.

Phân bố không gian đa tổn thương có sự tương quan cao với TDBTT đối với thiên tai đơn. Các địa phương có TDBTT rất cao đối với thiên tai đơn đều có mức độ đa tổn thương rất cao. Đa tổn thương có thể tăng $25 \%-105 \%$ so với TDBTT đối với thiên tai đơn GM. Điều này cho thấy khi chịu tác động của các thiên ta xảy ra đồng thời/nối tiếp, TDBTT của khu vực tăng lên đáng kể. Do đó, đối với những khu vực thường bị ảnh hưởng bởi các thiên tai xảy ra đồng thời/nối tiếp, cần đánh giá đa tổn thương gây bởi các thiên tai này. Cách tiếp cận này tránh tình trạng đánh giá dưới mức thực tế dẫn đến gia tăng thiệt hại do đa thiên tai gây ra.
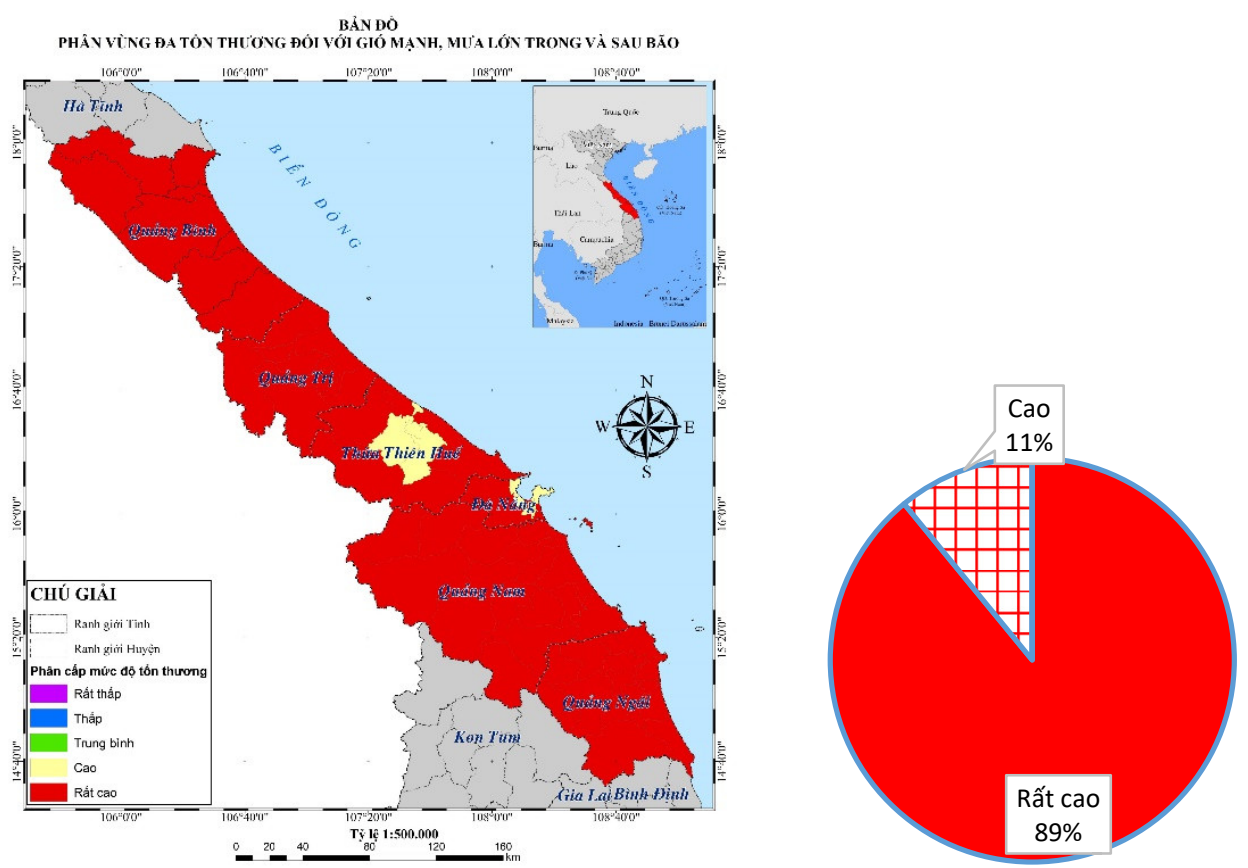

Hình 8. Phân vùng đa tổn thương.

Các bản đồ phân vùng đa tổn thương cho phép dễ dàng so sánh mức độ đa tổn thương giữa các huyện, cung cấp cơ sở nhận định khu vực nào nên được xem xét ưu tiên nâng cao năng lực chống chịu đối với đa thiên tai, từ đó có cơ sở xây dựng kế hoạch phòng chống và giảm nhẹ rủi ro thiên tai hiệu quả hơn. Do khu vực Trung Trung Bộ có mức độ đa tổn 
thương rất cao, việc trang bị, lắp đặt hệ thống thông tin liên lạc tiên tiến để cảnh báo sớm và xây dựng nơi trú ẩn thích hợp để sơ tán khẩn cấp khi bị ảnh hưởng của bão là cần thiết. Người dân và chính quyền địa phương cần được nâng cao nhận thức và được đào tạo nhiều hơn nữa các kỹ năng sẵn sàng phòng chống thiên tai để giảm nhẹ thiệt hại do thiên tai gây ra trong tương lai. Khi có nguy cơ bị ảnh hưởng của bão, nếu công tác dự báo cường độ gió và lượng mưa liên tục được cải thiện về độ chính xác, nhưng việc công bố thông tin không kịp thời hoặc theo các hình thức quần chúng không thể tiếp cận được vẫn sẽ gây khó khăn trong việc phòng chống và giảm nhẹ thiệt hại do đa thiên tai. Do đó, việc nâng cao chất lượng dự báo thiên tai và công tác truyền tin cần được thực hiện song song, đồng bộ để giảm thiệt hại do thiên tai gây ra.

Do tính sẵn có của số liệu tại khu vực nghiên cứu còn hạn chế, một số chỉ số chưa được xem xét đến trong nghiên cứu này gồm: Tỷ lệ đóng góp GDP của ngành nông nghiệp, diện tích rừng phòng hộ ven biển, tỉ lệ nhà kiên cố, số lượng lớp tập huấn về thiên tai. Ngoài ra, tỷ lệ người dân sử dụng điện thoại di động, internet dù đã được xem xét trong nghiên cứu, nhưng những chỉ số này chỉ phản ánh công cụ truyền tin. Thời gian và nội dung thông tin chuyển tải cũng đóng vai trò quan trọng trong việc giảm nhẹ và phòng tránh thiên tai vẫn chưa xem xét trong nghiên cứu này. Do đó, khi điều kiện số liệu được cải thiện, các nghiên cứu sau nên có thể đánh giá đầy đủ hơn.

\section{Kết luận}

Việc áp dụng phương pháp đánh giá định lượng đa tổn thương dựa trên bộ chỉ số kinh tế-xã hội-môi trường có xét đến sự gia tăng TDBTT đối với các thiên tai xảy ra đồng thời và nối tiếp đã xác định được mức độ đa tổn thương của từng huyện thuộc các tỉnh ven biển Trung Trung Bộ đối với gió mạnh, mưa lớn trong và sau bão. Đây là nỗ lực đầu tiên để đánh giá định lượng đa tổn thương cho 64 huyện thuộc 6 tỉnh ven biển ở Trung Trung Bộ. Kết quả cho thây $89 \%$ các huyện ở Trung Trung Bộ có mức độ đa tổn thương rất cao, do đó, các giải pháp nhằm giảm độ nhạy cảm, tăng nguồn lực của khu vực là nhiệm vụ cần thiết và cấp bách, mang tính liên huyện, liên tỉnh. Cách tiếp cận của nghiên cứu này đánh giá được TDBTT không chỉ đối với thiên tai đơn mà còn đánh giá được đa tổn thương và cho phép xây dựng bản đồ phân vùng đa tổn thương ở quy mô cấp huyện. Kết quả đánh giá đóng vai trò như một công cụ hỗ trợ quá trình ra quyêt định liên quan đến công tác giảm nhẹ, phòng chống thiên tai và phát triển kinh tế bền vững ở khu vực nghiên cứu, cung cấp thêm cơ sở để các nhà ra quyết định cân nhắc, điều chỉnh và định hình các quy hoạch, kế hoạch, chính sách hiện hành hướng tới sự phát triển bền vững của địa phương.

Do đa tổn thương phụ thuộc nhiều vào điều kiện kinh tế-xã hội-môi trường và nguồn lực của địa phương trong việc ứng phó và khắc phục hậu quả do thiên tai gây ra, kết quả phân bố không gian và các chỉ số đa tổn thương trong nghiên cứu này chỉ có ý nghĩa áp dụng đối với các tỉnh ven biển Trung Trung Bộ. Đối với các khu vực nghiên cứu khác, cần rà soát, cập nhật thông tin các chỉ số đánh giá, từ đó xây dựng được bản đồ phân vùng đa tổn thương, phục vụ cho công tác phòng chống và giảm nhẹ thiên tai, phát triển bền vững của khu vực nghiên cứu. Phương pháp được áp dụng trong nghiên cứu này có thể áp dụng đánh giá đa tổn thương cho các khu vực ven biển khác.

Đóng góp của tác giả: Xây dựng ý tưởng nghiên cứu: T.T.; Lựa chọn phương pháp nghiên cứu: T.T.T, T.T., H.T.L.H.; Xử lý số liệu: T.T.T.; Viết bản thảo bài báo: T.T.T.; Chỉnh sửa bài báo: T.T.T, T.T., H.T.L.H.

Lời cảm ơn: Kết quả nghiên cứu này được hỗ trợ bởi Đề tài "Nghiên cứu các giải pháp khoa học và công nghệ quản lý đa thiên tai, xây dựng công cụ hỗ trợ ra quyết định ứng phó với đa thiên tai, áp dụng thí điểm cho khu vực ven biển Trung Trung Bộ" (mã số: KC.08.24/16-20) thuộc Chương trình khoa học và công nghệ cấp quốc gia giai đoạn 2016- 
2020 "Nghiên cứu khoa học và công nghệ phục vụ bảo vệ môi trường và phòng tránh thiên tai" (KC.08/16-20).

Lời cam đoan: Tập thể tác giả cam đoan bài báo này là công trình nghiên cứu của tập thể tác giả, chưa được công bố ở đâu, không được sao chép từ những nghiên cứu trước đây; không có sự tranh chấp lợi ích trong nhóm tác giả.

\section{Tài liệu tham khảo}

1. Lee, Y.S.; Liou, Y.A.; Liu, J.C.; Chiang, C.T.; Yeh, K.D. Formation of Winter Super Typhoon Haiyan (2013) and Hagupit (2014) through interaction with cold fronts as observed by Multifunctional Transport Satellite. IEEE Trans. Geosci. Remote Sens. 2017, 55, 3800-3809. https://doi.org/10.1109/TGRS.2017.2680418.

2. Liou, Y.A.; Nguyen, A.K.; Li, M.H. Assessing spatiotemporal eco-environmental vulnerability by Landsat data. Ecol. Indic. 2017, 80, 52-65. https://doi.org/10.1016/j.ecolind.2017.04.055

3. Liou, Y.A.; Liu, J.C.; Liu, C.P.; Liu, C.C. Season-dependent distributions and profiles of seven super-typhoons (2014) in the Northwestern Pacific Ocean from satellite cloud images. IEEE Trans. Geosci. Remote Sens. 2018, 56, 2949-2957, https://doi.org/10.1109/TGRS.2017.2787606.

4. Thục, T.; Neefjes, K.; Hương, T.T.T.; Thắng, N.V.; Nhuận, M.T.; Trí, L.Q.; Thành, L.Đ.; Hương, H.T.L.; Sơn, V.T.; Thuận, N.T.H.; Tường, L.N. Báo cáo đặc biệt của Việt Nam về Quản lý rủi ro thiên tai và hiện tượng cực đoan nhằm thúc đẩy thích ứng với $\mathrm{BĐKH,} \mathrm{Viện} \mathrm{Khoa} \mathrm{học} \mathrm{Khí} \mathrm{tượng} \mathrm{Thủy} \mathrm{văn} \mathrm{và} \mathrm{Biến} \mathrm{đổi} \mathrm{khí} \mathrm{hậu} \mathrm{và}$ UNDP. NXB Tài nguyên Môi trường và Bản đồ, Hà Nội, 2015.

5. Ban chỉ đạo Phòng chống lụt bão Trung ương. Báo cáo về bão số 9 Ketsana, 2009.

6. UNISDR. Terminology on Disaster Risk Reduction. United Nations International Strategy for Disaster Reduction. Accessed March 2019 from https://www.unisdr.org/we/inform/terminology

7. Pielke, R.A.J. Rethinking the role of adaptation in climate policy. Global Environ. Change 1998, 8, 159-170. https://doi.org/10.1016/S0959-3780(98)00011-9.

8. Williams, G. Study on Disaster Risk Reduction, Decentralization and Political Economy. Global Assessment Report on Disaster Risk Reduction (GAR), 2011.

9. Gautam, D. Assessment of social vulnerability to natural hazards in Nepal. Nat. Hazards Earth Syst. Sci. 2017, 17, 2313. https://doi.org/10.5194/nhess-17-23132017

10. Alpar, B. Vulnerability of Turkish coasts to accelerated sea-level rise. Geomorphology 2009, 107, 58-63.

11. Mahendra, R.S.; Mohanty, P.C.; Bisoyi, H.; Kumar, T.S.; Nayak, S. Assessment an management of coastal multi-hazard vulnerability along the CuddaloreVillupuram, east coast of India using geospatial techniques. Ocean Coast Manag. 2011, 54, 302-311. https://doi.org/10.1016/j.ocecoaman.2010.12.008.

12. Gallina, V. An advanced methodology for the multi-risk assessment: an application for climate change impacts in the North Adriatic case study (Italy). PhD Thesis, University of Vienna, 2015.

13. Mafi-Gholami, D.; Zenner, E.K.; Jaafari, A.; Bakhtyari, H.R.R.; Bui, D.T. Multi hazards vulnerability assessment of southern coasts of Iran. J. Environ. Manage. 2019, 252, 109628. https://doi.org/10.1016/j.jenvman.2019.109628.

14. GIZ. Risk Supplement to the Vulnerability Sourcebook, 2017.

15. Tổng cục Thông kê Việt Nam Kết quả toàn bộ Tổng điều tra Dân số và Nhà ở Việt Nam năm 2019, 2019. 
16. Fritzsche, K., Schneiderbauer, S., Bubeck, P., Kienberger, S., Buth, M., Zebisch, M., \& Kahlenborn, W. The Vulnerability Sourcebook: Concept and guidelines for standardised vulnerability assessments, 2014.

17. Tăng Thế Cường. Luận án tiến sĩ Nghiên cứu tích hợp vấn đề biến đổi khí hậu vào quy hoạch phát triển kinh tế - xã hội của tỉnh Thừa Thiên Huế qua đánh giá môi trường chiến lược. Viện Khoa học Khí tượng Thủy văn và Biến đổi khí hậu, 2015.

18. Liu, Z.; Nadim, F.; Garcia-Aristizabal, A.; Mignan, A.; Fleming, K.; Luna, B.Q.A. Three-level framework for multi-risk assessment. Georisk: Assess. Manage Risk Engineered Syst. Geohazards 2015, 13, 59-74. https://doi.org/10.1080/17499518.2015.1041989

19. Gallina, V.; Torresan, S.; Critto, A.; Sperotto, A.; Glade, T.; Marcomini, A. A review of multi-risk methodologies for natural hazards: Consequences and challenges for a climate change impact assessment. J. Environ. Manage. 2016, 168, 123-132. https://doi.org/10.1016/j.jenvman.2015.11.011

\title{
Multi-hazard vulnerability assessment of Mid-Central Coast
}

\section{Tran Thanh Thuy ${ }^{1}$, Tran Thuc ${ }^{1}$, Huynh Thi Lan Hương ${ }^{1}$}

1 Viet Nam Institute of Meteororlogy, Hydrology and Climate Change; thuybk77@gmail.com, tranthuc.vkttv@gmail.com, huynhlanhuong@gmail.com

\begin{abstract}
Natural disasters often occur simultaneously, cascadingly, or cumulatively. Mid-central coast provinces are frequently affected by natural disasters such as typhoons, extreme precipitations, etc. There have been many studies on natural disasters and vulnerability to disaster, however, they only consider an individual hazard, but multihazards. This study quantitatively assesses the socio-economic vulnerability of the midcentral coast to typhoons and typhoon-precipitation and non-typhoon-precipitation (multi-hazards). The results indicate that $86 \%$ of districts in the mid-central region are classified into high and very high vulnerable classes to typhoon-windspeed (GM) or typhoon-precipitation (MTB) and 50\% to non-typhoon precipitation (MSB). The vulnerability index to GM/MTB and MSB ranges from $0.11-0.39$ and $0.02-0.47$, respectively. Vulnerability to multi-hazards increased, $100 \%$ of districts are classified into high and very high multi-vulnerable classes, the multi-vulnerability (MV) index ranges from $0.18-0.49$. MV can be $25 \%-105 \%$ higher than vulnerability to a single natural disaster. Therefore, it is a necessary and urgent task to have solutions to reduce the sensitivity and increase the capacity of the research area. The approach of this study allows in-depth and multi-faceted explorations of vulnerability to not only single hazard but also multi-hazards, allowing the development of multi-vulnerability zoning maps at the district level and could aid in more effective planning, resource management, and inter-district coordination to mitigate damages caused by multiple natural disasters.
\end{abstract}

Keywords: Multi-hazard; Typhoon; Extreme precipitation; Vulnerability; Multivulnerability. 